\title{
Formação de professores de matemática: um contributo da engenharia didática (ED)
}

\author{
Mathematics teacher training: a contribution of didactic engineering (ED) \\ Francisco Regis Vieira Alves \\ fregis@ifce.edu.br \\ Marlene Alves Dias \\ maralvesdias@gmail.com
}

\begin{abstract}
Resumo
De modo inconteste, a vertente francófona proporcionou um avanço e pormenorização do trato operacional e científico, concernentemente ao âmbito do ensino e da aprendizagem em Matemática, para seus diversos níveis. Num período temporal que requereu algumas décadas, contatamos um interesse distinguido na produção controlada de fenômenos oriundos das interações do trinômio professor - estudantes - conhecimento matemático. Desta forma, a partir de uma preocupação especial com a ação e a modelização das ações do professor, o presente trabalho discute alguns elementos visivelmente condicionados por uma perspectiva de Engenharia Didática de $2^{\mathrm{a}}$ geração ou Engenharia de Formação. Por conseguinte, a partir de uma atenção maior que se deslocou da Engenharia Clássica ou de $1^{\text {a }}$ geração, que se ocupava eminentemente de uma ação de produção de dispositivos, tendo em vista o acumulo de saberes relacionados com o ensino de determinado conteúdo, passamos a observar na literatura especializada, sobretudo, na literatura internacional, a forte indicação de uma nova preocupação com a produção de recursos educativos e o aperfeiçoamento profissional do professor de Matemática. Ademais, ao assumir o professor de Matemática como um ator importante no processo, o trabalho apresenta implicações para a sua mediação, balizada por alguns dos pressupostos da transposição didática (CHEVALLARD, 1991).
\end{abstract}

Palavras chave: Engenharia didática; Engenharia de formação; Ensino; Professores de matemática.

\begin{abstract}
Undoubtedly, the francophone aspect provided an advance and detail of the operational and scientific treatment, concerning the scope of teaching and learning in Mathematics, for its various levels. In a temporal period that required some decades, we contacted a distinguished interest in the controlled production of phenomena originating from the trinomial interactions of teacher - students - mathematical knowledge. Thus, from a special concern with the action and modeling of teacher actions, the present work discusses some elements visibly conditioned by a 2nd generation Didactic Engineering perspective or Training Engineering. Therefore, from a greater attention that shifted from Classical Engineering or 1st generation, which was eminently concerned with an action of device production, in view of the accumulation of knowledge related to the teaching of certain content, we began to observe In the specialized literature, especially in the international literature, the strong indication of a new concern with the production of educational resources and the professional improvement of the Mathematics teacher. In addition, in assuming the teacher of Mathematics as an important actor in the process, the work has implications for its mediation, which is guided by some of the presuppositions of didactic transposition (CHEVALLARD, 1991).
\end{abstract}

Key words: Didactical engineering; Trainning engineering; Teaching; Mathematical teachers.

\section{Introdução}

De modo inequívoco, registramos a constituição e o reconhecimento de um campo de estudos e investigações que, no Brasil, recebeu a denominação de Educação Matemática, 
enquanto que, concernentemente à sua dependência de suas origens anglo-saxônicas ou francófonas, podemos denominar de Didática da Matemática (DM). Assim, aqui em nosso país, a despeito de algumas décadas do alcance de um patamar do rigor e austeridade técnico e científica nas investigações sobre o ensino e aprendizagem em Matemática, em seus diversos níveis, aparentemente, as repercussões e implicações concretas e efetivas em sala de aula, se mostram ou se evidenciam inexistentes, tímidas e/ou extremamente localizadas.

De um ponto de vista quase "genético", em sua constituição europeia, os primeiros estudos desenvolvidos, sobretudo na França, nas décadas dos anos de 1960, 1970 e 1980, manifestaram um forte interesse declarado pelas interações do trinômio "estudante - professor - conhecimento matemático". Por conseguinte, poderemos depreender que, em maior ou em menor substancia, o principal agente social capaz de efetivar e operacionalizar um rico repertório de teorias e modelos de transposição (e mediação), em sala de aula, indicada no trinômio anterior é o professor. Outrossim, poderemos compreender, ainda, os elementos que concorrem para um certo viés de ineficacidade, inércia ou, até mesmo, da lentidão de uma repercussão esperada dos esforços científicos encetados por vários especialistas do território nacional, com o escopo do aperfeiçoamento profissional do mesmo.

Desta forma, além de nos determos no entendimento de alguns entraves e bloqueios que atuam no sentido de repercutir de modo limitado, na pesquisa em Educação Matemática, deter-nos-emos a um expediente de apreciação da Engenharia Didática de $2^{\mathrm{a}}$ geração que, conforme nosso entendimento, apresenta o poder epistêmico e de aderência legítima e necessária, a fim de possibilitar um efeito nitidamente mais representativo para o ensino de Matemática, sobretudo, no locus acadêmico. Sem mais delongas, na seção subsequente, abordaremos um pouco do percurso histórico da Engenharia Didática (ED).

\section{Engenharia Didática (ED)}

Quando nos atemos ao ofício de professor (de Matemática), propugnamos três momentos ou fases imprescindíveis, insubstituíveis e fundamentais, a saber: a preparação/concepção, a realização de uma mediação em sala de aula, e a avaliação das etapas predecessoras, em seu conjunto e de modo individual (e local). Certamente que empregamos um modelo prosaico para o entendimento da dialética recorrente da trajetória anterior. Ademais, em nossos trabalhos (ALVES, 2016), buscamos fazer agregar maior relevância ao principal contexto de atuação e o que, de fato, consubstancia o ofício de professor (de Matemática), qual seja a sala de aula. 
De modo pormenorizado, e ainda com referência ao fenômeno da mediação em sala de aula, perspectivamos o momento da preparação. Aqui, devem concorrer um conjunto de variáveis epistêmicas e intimamente vinculadas ao conhecimento (matemático) que se enseja transmitir, evidentemente, com eficiência, bem como, os conhecimentos de ordem não epistêmica que, de um modo implícito ou explícito, devem modificar/condicionar a real e concreta transmissão em sala de aula.

No segundo momento, da transmissão em sala de aula, como mencionamos nos parágrafos predecessores, volta em cena o trinômio constituído por professor - estudantes conhecimentos (matemáticos). A partir do mesmo, devem se originar um conjunto de variáveis organizacionais da aula (micro-didáticas) (BROUSSEAU, 1978; 1994; 1995; 1996; 2000) que podem concorrer para impulsionar uma trajetória consistente, tendo em vista a incorporação (tácita) de saberes científicos, bem como, de outro modo, fatores que atuam negativamente e, mesmo, como elementos impeditivos e que cadenciam um progresso inercial, por vezes, letárgico ao conhecimento guiado pelas idiossincrasias dos estudantes.

Por fim, no terceiro momento, indicamos a etapa da avaliação da própria transmissão que, diferentemente de outras tendenciais e acepções generalistas, a avaliação não pode prescindir de parâmetros e critérios comparativos e de referências intimamente relacionados e vinculados com a Matemática, sob pena de que, quando apoiamo-nos em perspectivas generalistas e exógenas, podemos incorrer no risco de não desenvolver/elaborar um procedimento circunstanciado de apreciação dos dados produzidos antes, durante e depois da incursão do professor (pesquisador) em sala de aula.

Nos parágrafos anteriores descrevemos, de modo simplificado, um praxis eminentemente intrínseca ao professor de Matemática, não obstante, não revestida, em sua maioria das vezes, de um corpus técnico, científico e conceitual que proporcione vislumbrar as três fases clássicas indicadas há pouco, de modo local e global, a partir de um ponto de vista sistemático, pormenorizado e, principalmente, cientifico e "controlado".

Por último, sublinhamos o termo "controlado", posto que, por uma influência direta do modus operandi perpetrado no campo de pesquisa das Ciências Naturais, objetivamos que o rigor, continuamente perseguido, se consubstancia pelo controle/previsão e pela correspondente progressiva redução e/ou eliminação do caráter de subjetividade e despersonalização dos achados e/ou descobertas científicas.

Diante dessa perspectiva intrínseca ao progresso científico nas Ciências, trazemos um exemplo canônico discutido por Douady (1995) que constata um conjunto de enormes 
mudanças dos paradigmas da Matemática, sobretudo na França, em meados dos anos de 1930 até 1950. Num contexto de reformas, a autora aponta:

Se introduz, então, uma série de novas noções. É o caso das relações de equivalência sobre os conjuntos. Esta noção é poderosa, posto que, se realiza um quociente de um conjunto por uma relação de equivalência, assim, se podem construir novos conjuntos com suas respectivas estruturas. Desta forma, é possível produzir, por exemplo, os negativos e os racionais, a partir dos inteiros. (DOUADY, 1995, p. 3).

A noção matemática importante, apontada no excerto acima, constitui apenas a "ponta do iceberg" correspondente aos novos paradigmas disseminados pela academia e, consequentemente, no contexto escolar. Douady (1995, p. 2) comenta que o matemático francês Henri Léon Lebesgue (1875 - 1941), no início do século, manifestou sérias preocupações sobre as condições de ensino e a formação do professor. Os esforços mais recentes são desenvolvidos em todo os países. Menciona ainda que reformas de programas foram decididos, decisões pedagógicas tomadas. Nesse contexto preocupante, Douady recorda que "sob a impulsão de pesquisadores de horizontes diferentes: matemática, psicologia, ciências da educação, e também linguística, história, sociologia, sobretudo na França [...]” se observou forte mobilização de mudanças no campo do ensino de Matemática.

Dessa forma, a partir dos anos 80, foram criados na França, centros universitários, espalhados em todo o pais que, de modo prosaico, impulsionaram a organização e trabalho conjunto de vários profissionais, de matizes e formações variadas, realmente preocupados com melhorias no sistema de ensino. Chamados de Institutos de Pesquisa sobre o ensino de Matemática (Institut Universitaire de Recherche sur L'Enseignement des Mathématiques IREM), por intermédio do estabelecimento institucional e "transversal" desta estrutura de ideias possibilitou, segundo Douady (1984, p. 2), a evolução de pesquisas levando em consideração os três pólos: "professor, alunos de Matemática e sistema de ensino".

Diante do contexto anterior, grupos de estudiosos, de orientações distintas, atuaram, de um modo pioneiro, para a delimitação de uma esfera de atuação sistemática para lidar e compreender os diversos entraves, no seio das instituições, relacionados com o ensino de Matemática. Ademais, com uma consequência imediata do poder de aderência epistêmica com o conhecimento matemático, a constituição de uma identidade própria, de um conjunto de constructos técnicos e conceituais, relacionados com um interesse crescentes com os fenômenos originados no binômio ensino - aprendizagem.

Deparamos o surgimento da terminologia Engenharia Didática - ED que, a despeito da evolução de suas premissas, foi usada para designar/envolver um modus operandi de 
investigação ou ainda como "uma metodologia para a análise de situações didáticas" (ROBINET, 1983, p. 2). Recordamos que “o termo da Engenharia Didática designa um conjunto de sequências de classes concebidas, organizadas e articuladas no tempo, de maneira coerente por um professor-engenheiro, com o fim de realizar um projeto de aprendizagem para uma população determinada de alunos" (DOUADY, 1995b, p. 62). Cabe acentuar que, de acordo com Artigue (2015, p. 467), a "concepção de design de investigação e a regra precisa em uma pesquisa depende, fortemente, de uma cultura educacional”. E, neste caso, fazemos referência à cultura didática francesa (ARTIGUE, 2015).

Margolinas \& Drijvers (2015, p. 893) recordam que a Engenharia Didática (ED), na França, a disseminação e delimitação de um campo de estudos, direcionados e preocupados com os estilos de investigação e práticas de intervenção controladas, que passaram a receber o status de design de investigação, isto é, um paradigma metodológico que possa indicar o processo de condução sistemática de certas investigações que, quase de modo predominante, evolvem a intervenção nos espaços educacionais (GONDINO et all, 2013, p. 3). Logo mais adiante, Almouloud \& Silva (2012, p. 26) explicam:

[...] a noção de Engenharia Didática (clássica ou de primeira geração) emergiu na didática da matemática no início dos anos 1980. Primeiramente em 1982 por Yves Chevallard e Guy Brousseau, depois, em 1989, por Michèle Artigue. Ela foi apresentada como uma metodologia de pesquisa suscetível de fazer aparecer fenômenos didáticos em condições mais próximas possíveis do funcionamento de uma sala de aula clássica.

Se evidencia, pois, um interesse particular e especial pelo fenômeno "aula", como objeto de perquirição investigativa. Ademais, a despeito de um processo endógeno evolutivo da ED, apreciamos também um progressivo terreno de discussão que repercutiu nos mecanismos de investigação, tendo em vista o entendimento de entraves e obstáculos ao ensino/aprendizagem em Matemática, em seus diversos níveis. Nesse sentido, Artigue (1996, p. 265) observa:

A Engenharia Didática coloca problemas de natureza nova, pois, de um lado,
a realização experimental supõe, ela mesma, uma espécie de transmissão em
direção aos aprendizes, que devem ser os atores e, por outro lado, como
quadro de metodologias externas, não podemos importar facilmente o
'sentido' de reprodução de outros campos científicos específicos.

No trecho anterior, Artigue (1996) aponta o que, para o nosso entendimento, funciona como o "fio de Ariadne", diante do interesse da pesquisa e da formação em sala de aula. A perspectiva que precisa ser evidenciada, diz respeito ao caráter de aderência, adequabilidade e, sobretudo, robustez técnico-cientifica que garantem a repercussão dos quadros da ED apenas, e com maior ênfase, aos conteúdos matemáticos, sob pena de que, quando lidamos 
com outros campos epistêmicos do conhecimento cientifico (Física, Química, Biologia, etc), não garantimos o mesmo grau ou teor de eficacidade do aparato previsto por uma ED, posto que, a mesma foi pensada e formulada para o ensino de Matemática. Com uma perspectiva semelhante, Joshua \& Dupin (1993) denunciam, de modo semelhante, a mesma problemática, no trecho abaixo:

Isto conduz a uma abordagem didática que deverá se opor àquela que se revela a partir de uma pedagogia geral, na medida em que, no último caso, se interessaria pela busca de regras de aprendizagem e de educação que se mostram independentes do conteúdo preciso e visado para o ensino, considerando qualquer conteúdo em geral. Ao menos no caso de disciplinas complexas e altamente estruturadas, como as disciplinas científicas e as Matemáticas, se mostra pouco provável que um conhecimento pertinente possa ser dominado pela compreensão de fenômenos de ensino que deixam de lado os saberes específicos. (JOSHUA \& DUPIN, 1993, p. 3)

Com uma perspectiva acima semelhante à de Artigue (1993), os autores expressam acima o caráter de inadequabilidade e/ou incompatibilidade epistêmica concernentemente ao uso, de modo pouco cuidadoso e de caráter superficial, tendo em vista o emprego de modelos e concepções extraídas de outros campos epistêmicos, nomeadamente, àqueles das Ciências Humanas, para o entendimento dos fenômenos no seio de disciplinas específicas.

Em todo caso, retomando ainda as duas tendências distintas da Engenharia Didática clássica ou de $1^{\mathrm{a}}$ geração (ED1), compreendida como uma metodologia que visa o estudo dos fenômenos didáticos, que possam permitir os fenômenos em sala de aula, bem como, uma perspectiva de $\mathrm{ED}$, visando o desenvolvimento de recursos de formação que, segundo a tradição, tem recebido a denominação de Engenharia Didática de $2^{\mathrm{a}}$ geração (ED2). Restringir-nos-emos aos aspectos característicos relativos com a ED2. Nosso interesse maior se consubstancia a partir das esclarecedoras ponderações de Almouloud \& Silva (2012).

\footnotetext{
A engenharia didática de desenvolvimento é, segundo Perrin-Glorian (2009), ao mesmo tempo uma engenharia didática para o desenvolvimento de recursos e para a formação de professores envolvidos no projeto. $\mathrm{O}$ tamanho das engenharias é uma questão importante para a engenharia de desenvolvimento e a produção de recursos. Uma situação isolada pode ser desenvolvida facilmente, mas não se pode esperar um efeito positivo na prática dos professores, aliás este tipo de situações pode ter, às vezes, um efeito negativo nos processos de ensino e aprendizagem de conceitos matemáticos.
}

De modo inconteste, no trecho anterior, depreendemos um forte caráter de formação de professores intimamente relacionado com os objetivos de um ED2. Não obstante, o lugar privilegiado para o ensino e a para a aprendizagem se preserva incólume, entretanto, uma perspectiva que se enleva, neste contexto, refere-se ao processo de valorização da ação e da 
mediação, por parte do professor. E, pouco mais adiante, os mesmos autores completam que “a engenharia de desenvolvimento está fortemente ligada às investigações nos saberes matemáticos necessários aos professores para ensinar a matemática. É neste sentido que ela está ligada à formação”. (ALMOULOUD \& SILVA, 2012, p.32). A seguir, acentuaremos alguns elementos capazes de repercutir na formação e aperfeiçoamento de professores.

\section{Implicações e repercussões para a (engenharia) formação.}

Antes de restringir um expediente de discussão centrado no processo de formação profissional, cabe constatar algumas das influencias epistêmicas que, em maior ou em menor substância, concorreram para seu vigor científico da atualidade (GODINO et all, 2013; MARGOLINAS \& DRIJVERS, 2015). Para tanto, apreciamos as seguintes ponderações de Pastré, Mayen \& Vergnaud (2006, p. 146 - 147).

\footnotetext{
É um campo de práticas que consiste em construir dispositivos de formação correspondentes às necessidades identificadas, para um público dado, no quadro do seu meio de trabalho. A formação escolar possui, como tendência, a descontextualização das aprendizagens. A engenharia da formação deve, precisamente, insistir no contrário, sobre o contexto social, no qual devem ser efetuadas a aprendizagem dos adultos em formação. [...] A engenharia de formação se concretiza, principalmente, a partir de duas práticas: análise das necessidades e dos dispositivos de formação [...]
}

Oriundo de contexto ampliado, os autores acima discutem a tendência da didática profissional (didactique professionnelle) que, em sua origem, deve ser centrada nos dispositivos de formação de profissionais. Entretanto, tendo em vista nossa maior atenção aos dispositivos de formação do professor de Matemática pontuaremos, em seguida, uma breve trajetória evolutiva que revela certos elementos imprescindíveis para a formação que ensejamos discutir.

Desse modo, com amparo em um entendimento de um longo processo histórico que, do ponto de vista endógeno, teve início na pesquisa em Matemática dos anos 30. Passou, também, a se tornar visível e assumiu ênfase na replicação de determinados pressupostos técnico-epistemológicos, em todos os níveis de ensino de Matemática. Todavia, um "ponto de inflexão" pôde ser detectado no final dos anos 70, com origem em uma série de problemas registrados no contexto de efetivo funcionamento da novas mudanças e orientações sobre a natureza do conhecimento matemático que, em grande parte, foi discutido no interior da academia. Nesse sentido, Douady (1995a, p. 4) relata que:

Existia uma grande incerteza, por parte dos professores, porque os mesmos não sabiam o que deviam ensinar e tampouco sabiam que liberdade de ação se concederia ao aluno. Se encontravam bloqueados entre as várias alternativas. Se enfrentavam a exigência de rigor automático e temor de fazer afirmações que não se mostrassem corretas do ponto de vista 
matemático. Por outra parte, não sabiam que distância poderia tomar com o texto que dispunham. Isto gerava um esquema de ensino dogmático em que se seguia estritamente e se exigia dos alunos o que estava escrito no papel.

A constatação de uma profusão de entraves e bloqueios enfrentado pelos professores em exercício, no contexto escolar básico, se mostra claramente indicado acima. Visivelmente, os cânones de rigor e viés estruturalista bourbakista da Matemática (CHOQUET, 1963), rotineiramente empregados no locus acadêmico, passam a nortear, influenciar e determinar, também, o modus operandi do professor da escola básica. Em muitos casos, os roteiros e influencias primeiras registradas com tal viés, podem ser verificados e prescritos nos livros e compêndios didáticos, como podemos depreender abaixo:

\begin{abstract}
Ademais, não podemos aceitar que o debate seja limitado por uma única modificação do texto do conhecimento. Chevallard observa com razão que os professores concordam com uma confiança quase cega relativamente ao trato de uma dificuldade eficazmente, por meio de uma única reorganização do texto do saber. É ao contrário que um conjunto solidário de características de uma situação de ensino pode produzir seus efeitos, e não apenas o texto do saber. Para preservar sua pertinência, o julgamento sobre uma transposição deve aguardar por sua colocação em prática [...]. (JOSHUA \& DUPIN, 1993, p. 209)
\end{abstract}

A noção de transposição didática indicada no trecho e introduzida no referencial francês de modo pioneiro por Chevallard (1991) proporcionou uma perspectiva sui generis para a análise dos fenômenos envolvendo o trinômio saber - estudante - professor. Tal noção carrega, de modo latente que, em um repertório de extensos fenômenos envolvidos no ensino, os conhecimentos que precisam ser considerados extrapolam, de per si, o conhecimento matemático. Esse ponto de vista pode ser observado nas ponderações de Joshua \& Dupin (1993).

Podemos avançar sobre a hipótese que, didaticamente, o problema se resume em transmitir a gestão do modelo para o professor e sua utilização (prática ou conceitual) pelo o aluno e pela classe. Para tanto, se torna necessário que a classe admita um modelo como válido, como foi admitido no problema inicial. Mais precisamente, que a classe admita como válida cada etapa da construção e da transmissão do modelo. [...]. (JOSHUA \& DUPIN, 1993, p. 205)

Não podemos presumir o estabelecimento de um conjunto de práticas sistemáticas investigativas isentas de suas raízes histórico-culturais próprias. No caso de nossa apreciação corrente, tomamos como referência a vertente francófona de Educação Matemática ou da Didática da Matemática. E, em relação ao assunto, Artigue (2015) constata tanto a negação de paradigmas generalistas e "academicamente exportados" de outros campos epistêmicos ou áreas de conhecimento, bem como um movimento de demarcação e consolidação da área própria de atuação. O ponto de vista que apreciamos abaixo expressa, além de uma 
preocupação para a determinação de uma identidade científica e um campo de investigação francês, a demarcação de uma esfera de práticas que passam a configurar a ação de um novo ator, que nomearemos por professor-pesquisador. De fato, constatamos:

Pesquisadores franceses expressaram preocupações sobre a tendência observada para privilegiar metodologias emprestadas de campos estabelecidos como psicologia (entrevistas clínicas, questionários, pré-teste e comparações pós-teste ...) para assegurar a legitimidade cientifica da pesquisa em Educação Matemática. Eles apontaram que a Didática da Matemática é um autêntico campo científico cujas metodologias devem estar em consonância com o seu propósito específico: o estudo da disseminação intencional do conhecimento matemático através da didática e sistemas e a interação associada entre processos de ensino e aprendizagem. (ARTIGUE, 2015, p. 468).

Os estudos em Didática da Matemática, com origem na vertente francófona, distinguem determinados fenômenos, intrinsicamente relacionados e dependentes da Matemática e que se mostram consubstanciados a partir das interações oriundas do trinômio professor - estudantes - conhecimento (savoir-conaissance). De fato:

Durante a construção progressiva do conhecimento, a utilidade inicial do conhecimento em situações é gradualmente esquecida. O conhecimento é formalizado, o que é muito importante em ordem da criação de um corpo coerente de conhecimentos, conhecido como Matemática. Todavia, se você precisa usar a Matemática para resolver um problema, você tem que entender sua utilidade em situações problema, o que e bastante diferente da compreensão da matemática formal. Assim, existe uma ligação dialética entre o conhecimento formalizado (Savoir) e conhecimento em situação (connaissance). (ARTIGUE, 2015, p. 468).

Brousseau (1986) produziu um ponto de vista sui generis, tendo como atenção as interações que indicamos no trinômio professor - estudantes - conhecimento e com a correspondente introdução de uma metodologia de ensino de Matemática e a corresponde proposição de tipologias para o ensino ou fases para a mediação do professor, nominada de Teoria das Situações Didáticas - TSD.

. Cabe a distinção que, na cultura francesa, existe a distinção entre termos como savoir e connaissance. Artigue (2015) recorda um legítimo interesse dos estudos na França, envolvendo um conjunto de práticas científicas que possuem um profundo interesse na produção/replicação e controle de um determinado fenômeno, oriundo das interações dos elementos do trinômio, cuja origem pode ser perspectivada em Gaston Bacherlard (1884 1962), nominada, segundo Artigue (2015, p. 468 - 468) de "fenômenotecnológico" (phénoménotechnique).

Para exemplificar, trazemos um estudo recente de Tempier (2016) que apresenta dados de uma investigação balizada pela ED que pode ser enquadrada no viés de $2^{\mathrm{a}}$ geração, posto que, Tempier (2016) manifestou o interesse "em uma metodologia que leva em consideração 
ciclos de concepções de uma fonte e experimentos para professores, mediante a comparação da análise a priori e a posteriori”. Tempier (2016, p. 263) recorda o problema levantado, originalmente, pela autora Margolinas et all (2011), na França, tendo em vista a dificuldade de disseminação dos pressupostos da ED como produtos efetivos para o ensino atual. Neste sentido, "o problema não é apenas o relacionado à determinação e implementação dos princípios teóricos que orientam a engenharia didática. Também está relacionado às possibilidades para que os professores adaptem esses princípios às condições de ensino comuns " (PERRIN-GLORIAN, 2011, p. 60).

Tempier (2016, p. 264) recorda que Perrin-Glorian propôs a metodologia de ED para o acumulo de fontes de recursos primários para a formação de professores. O caráter de imprescindibilidade comentado por Tempier repousa em duas questões fundantes: (a) A relevância das situações: as situações permitem que os alunos construam o conhecimento matemático pretendido (como nas engenharias de $1^{\mathrm{a}}$ geração); (b) A adaptabilidade (e reprodução/replicação) das situações ao ensino comum: que as adaptações realizadas pelos professores durante a implementação das situações (como nas engenharias de $2^{\mathrm{a}}$ geração).

$\mathrm{Na}$ figura abaixo, acentuamos o movimento sistemático de investigação assumido do trabalho de Tempier (2016) e, de modo standard, como nos trabalhos em ED, empregou a Teorias das Situações Didáticas - TSD em caráter de complementaridade. No nível superior podemos divisar a noção de situação fundamental (Fundamental situation) teorizada em vários trabalhos de Brousseau (1986). No segundo nível, ao lado esquerdo, observamos a fonte dos experimentos (Resource design) envolvendo as situações concebidas para aplicação didática. Por fim, ao lado direito e no segundo nível, Tempier objetivou o papel do experimento previsto por uma ED (Experiment) que, de modo prosaico, consistem de situações didáticas controladas e implementadas pelo professor em sala de aula.

Figura 1: Tempier (2016, p. 264) discute os momentos sistemáticos de um ED.

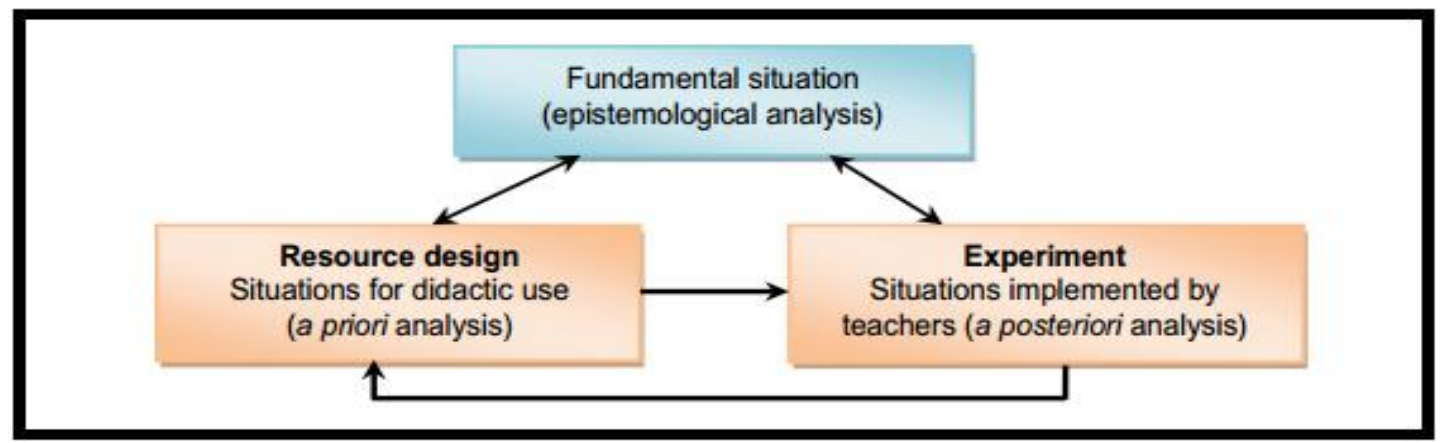

A tradição francesa confere e dedica um processo temporalmente prolongado para o desenvolvimento e finalização de uma ED1, sobretudo, quando assume maior interesse na aprendizagem dos estudantes. De fato, em consonância com sua essência histórica, a ED se 
preocupa com um processo que "se interessa pela ação de realizações didáticas em sala de aula, em forma de sequências" (ARTIGUE, 2015, p. 468), tendo como pressupostos as fases de análises preliminares, análise a priori, experimentação, análise a posteriori, envolvendo a validação interna e validação externa (LABORDE, 1999) do aparato construído. Neste sentido, divisamos, logo em seguida, profícuas repercussões para a ação do professor, tendo em vista o uso desta dialética:

A confrontação da análise a posteriori do desenvolvimento com a análise a priori conduz a uma modificação de situações. $\mathrm{O}$ novo processo pode ser levado à cabo pelo mesmo professor, no ano seguinte, conduz a uma evolução dos conhecimentos dos estudantes mais próximos da evolução desejada, mas, permite ainda, a revelação de resistências: resistências das concepções dos estudantes e no contrato didático usual em Geometria, mas, também, resistências, mediante às intervenções do professor. (PERRINGLORIAN, p. 61).

O trecho anterior permite extraímos múltiplas repercussões oriundas que, de modo natural pelo exposto, incidem, de modo natural, no contexto da sala de aula. Com efeito, Perrin-Glorian (2011) apontam acima dois elementos importantes. O primeiro confere ao papel ativo do professor (pesquisador), como produtor de situações didáticas e o cuidado redobrado com sua própria obsolescência. O segundo aspecto pode ser endereçado e compreendido nas práticas investigativas que demandam um tempo prolongado de acompanhamento dos sujeitos da amostra da ED e que se mostra reveladores da presença de obstáculos epistemológicos (BARCHELERD, 1996) e concepções mal adaptadas e/ou indesejadas.

No trecho anterior, Perrin-Glorian (2011) desenvolveu interesse particular pela transposição didática e a mediação dos conhecimentos da Geometria Plana. Desse modo, na seção subsequente, buscaremos explicitar aspectos característicos e alguns fenômenos intrínsecos da mediação dos saberes e a praxis do professor de Matemática, tendo em vista a próprio processo de transmissão dos saberes.

\section{Transposição didática na ED2.}

Delineamos um cenário das investigação e evolução dos modelos investigativos, que culminaram com um processo de nítida subdivisão e especialização de duas perspectivas distinguidas por ED1 e ED2. Ademais, apontamos ainda um papel fundamental para sua repercussão na formação de professores. Por outro lado, diante de uma profusão de elementos produzidos a partir de fenômenos multifacetados como o ensino e a aprendizagem, assinalamos nossa atenção direcionada para uma ação visceral e que consubstancia o oficio do 
professor, a saber: a transposição didática dos conhecimentos matemáticos. Logo abaixo, observamos algumas dificuldades e entraves na mudança de percepção necessária, oriunda de uma ampliação do quadro de preocupações de uma ED.

$\mathrm{Na}$ pesquisa educacional, incluindo as engenharias, sempre se relacionam com o professor, como um "participante ou é o destinatário dos trabalhos. Mas o papel do professor como um "objeto modalizável" foi de longa e de difícil construção. Eu irei situar inicialmente localizado no meu primeiro trabalho sobre este assunto no âmbito da pesquisa para o desenvolvimento da teoria das situações, E irei expor, em particular, as dificuldades do papel do professor conhecido dede o início dos anos 90. (MARGOLINAS, 2004, p. 12).

Como podemos depreender do fragmento acima, Margolinas (2004) aponta uma perspectiva necessária, todavia, que requereu muito tempo de acumulo de conhecimentos em torno da experiência de aplicação e construções de engenharias didáticas que, segundo a perspectiva francesa, o período temporal de desenvolvimento e obtenção de dados requer um lapso temporal bem mais prolongado, quando comparamos a mesma sistemática e procedimentos incorporados na experiência aqui no Brasil. Margolinas (2004) acrescenta ainda:

Mas, a instituição desta engenharia de formação, que é talvez a invenção específica da formação profissional contínua nos seus trinta anos de existência instituída, deixou na estrada outro projeto, igualmente importante, mas sem dúvida menos urgente: a constituição de uma engenharia didática profissional, cujo objetivo é utilizar a análise do trabalho para construir conteúdos e métodos, visando à formação das competências profissionais. Assim, até os anos 80, deixou-se para atrás a necessidade de reconsiderar o ato didático, voltado para os adultos ao trabalho, em referência ao desenvolvimento das competências e da experiência profissional. Pode-se pensar - [...] - que esta questão voltada para a engenharia didática profissional se tornou a urgência de hoje. (MARGOLINAS, 2004, p. 23).

Pastré (2004, p. 465 apud CHEVALLARD, 2009, p. 85-86) explica seu forte componente situado na formação de professores, quando observou também:

A formação contínua tem uma tradição de engenharia de formação que é praticamente tão longa que a sua própria história. Analisar um pedido, analisar necessidades, construir um dispositivo de formação, proceder à sua avaliação: tantas atividades de engenharia que são um pouco as cartas de nobreza da formação profissional contínua. Porque esta é constituída historicamente como um campo de práticas, trata-se de práticas analisadas e bem pensadas, que a própria área inventou e codificou.

O pensamento expresso no exceto anterior confirma uma longa e duradoura preocupação da vertente da Didática da Matemática com o fenômeno "aula de Matemática". Com efeito, em vários de nossos trabalhos (ALVES, 2016), temos assinalados que, em um rol de cenários de aprendizagem que podem ser classificados como primários, secundários, 
terciários e etc, em que temos a expectativa de atuação do mestre, propugnamos que o principal cenário e primário, envolvendo a inserção do professor é, precisamente, a sala de aula. Não obstante, ainda deparamos discursos academistas que ora se ocupam do questionamento da formação inicial ou continuada, etiquetando-a como "bacharelesca" ou "formação conteudista" e que, a despeito de assumirem alguns pressupostos pseudoacadêmicos, em termos de formação profissional, de modo patológico, adquirem espaço e atenção, apenas na formação de professores de Matemática. O que chamamos de "miopia acadêmica" se revela na falta de oportunidade de seguirmos o exemplo emblemático francês, com a valorização e busca de primados técnicos científicos que expliquem o fenômeno "aula", posto que, se mostra inexequível um controle intencional das aprendizagens dos estudantes dentro da sala de aula.

E, no esteio do pensamento anterior, a importância de um entendimento sobre o controle, a antevisão e definição de fatores que permitem a replicação das transposições didáticas minuciosamente construídas pelo professor de Matemática se mostra indubitável. Com efeito, os autores Bosch \& Gascon (2006) apontam algumas variáveis que incidem e repercutem, de modo irremediável, no interior da sala de aula, tendo em vista que:

Uma das primeiras contribuições da teoria das transposições didáticas foi tornar claro que não se torna possível interpretar a Matemática escolar com propriedade sem considerarmos o fenômeno considerado com a reconstrução escolar da Matemática, cuja origem deve ser encontrada nas instituições aonde vemos a produção de conhecimento matemático. (BOSCH \& GASCON, 2006, p. 55).

Um entendimento sobre o controle, o caráter da imprescindibilidade da antevisão de possíveis obstáculos epistemológicos e a correspondente definição de fatores que permitem e concorrem para a replicação das transposições didáticas, minuciosamente construídas pelo professor, assumem um papel imprescindível de destaque. Desse modo, Bosch \& Gascon (2006) indicam na figura abaixo uma trajetória extensamente teorizada e discutida por Chevallad (1991). No primeiro nível (primeiro diagrama) divisamos o conhecimento escolar estabelecido, tornado e indicado como válido e atual, em uma determinada instituição. Aqui, se mostra visível um corpus teórico de conhecimentos declarado no currículo e que deve ser transmitido para cada geração de estudantes assim, chegamos no segundo diagrama (ver figura 1). No terceiro diagrama (quando consideramos da esquerda para direita), devemos deparar um conjunto fenômenos de modificações e personalizações que permitem a configuração particular, relativamente a determinado grupo de estudantes e que pode ser percebido como conhecimento ensinado (taught knowledge) efetivamente em sala de aula. 
Por fim, ao lado direito, divisamos o estágio final de um conjunto de alterações que devem concorrer, ao final, a um conjunto de conhecimento efetivamente internalizados e, de modo concomitante, todo o processo didático anterior envolve um reinício do processo. Ademais, da trajetória indicada na figura divisamos, constatamos ainda uma análise sistemática e recorrentemente valorizada dos fenômenos institucionais e percursos e movimentos mais amplos, locais e sistemas de ensino em que registramos a presença do conhecimento matemático.

Figura 2: Conjunto de transformações sofridas pelos conhecimentos matemáticos.

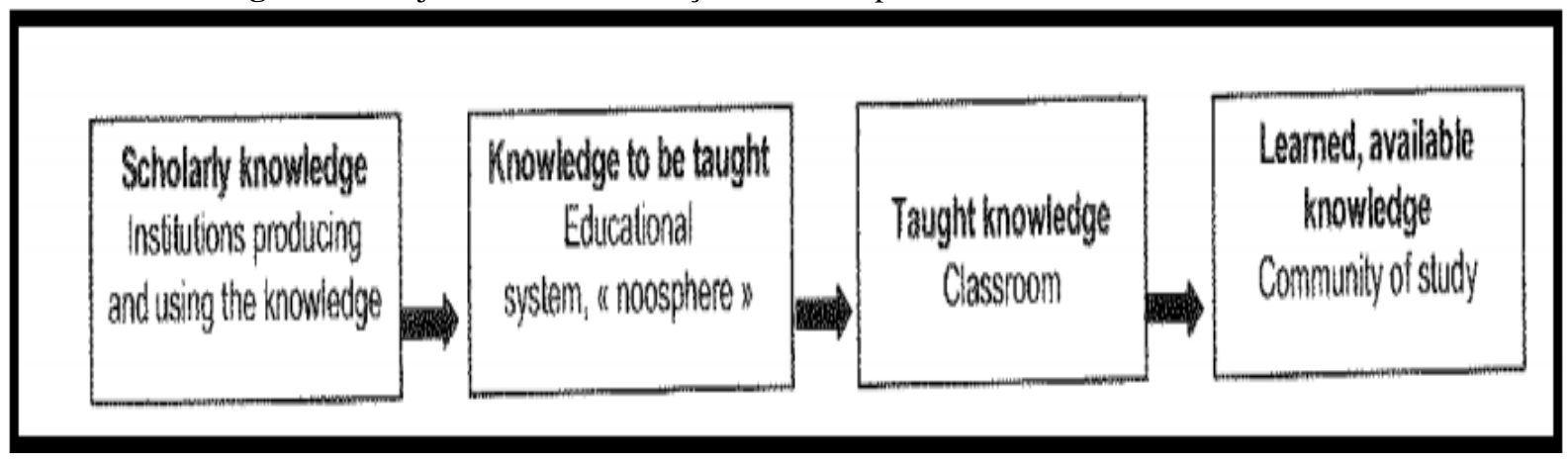

E. dessa forma, a partir de uma imprescindível contribuição da Teoria Antropológica do Didático - TAD (CHEVALLARD, 1982), a perspectiva de Chevallard permitiu um amplo campo sistemático de atuação e possibilidade de desenvolvimentos e aplicação de um aparato de investigação amparado por uma ED2. O autor desenvolveu uma espécie de "ecologia matemática" do estádio de descrição de suas praxeologias.

Dessa forma, a partir de uma imprescindível contribuição da Teoria Antropológica do Didático - TAD, a perspectiva de Chevallard permitiu um amplo campo sistemático de atuação e possibilidade de desenvolvimentos de um aparato de investigação amparado por uma ED2. O autor desenvolveu uma espécie de "ecologia matemática" do estádio de descrição de suas praxeologias. Com efeito, na figura 2, podemos vislumbrar os níveis, intimamente vinculados a um conjunto de fatores e determinantes que culminam, invariavelmente, com um cenário de aprendizagem e de encontro do professor, seus alunos e o as formas de conhecimentos escolares. Bosch \& Gascon (2006, p. 61) explicam que os níveis de determinação (ver figura 2), podem auxiliar "aos pesquisadores na identificação de avanço para um espaço restrito da sala de aula e o assunto para ser estudado".

“A engenharia não é, preliminarmente, a fonte de uma pesquisa, mas, se puder ser ou configurar-se, como uma condição para a pesquisa" (CHEVALLARD, 1982, p. 6). E, com origem nos elementos que indicamos nos parágrafos anteriores, que buscam demarcar alguns 
dos pressupostos relacionados com a transposição didática, depreendemos o caráter essencial de perspectivarmos uma ED2, assumindo os condicionantes clássicos e, em caráter de complementaridade, outras teorias associadas e que, no presente trabalho, comentamos a TAD.

Recentemente, Marty (2016) discutiu as noções de engenharia, engenharia pedagógica e a engenharia de formação que acentuamos de modo substancial nos parágrafos anteriores. Marty (2016, p. 3) apresentou a Engenharia Pedagógica - EP, em um contexto da ação do educador, ao decurso de um percurso formativo. Enquanto que a ED1 e a ED2 manifestam um interesse situado e circunstanciado pela Matemática e os fenômenos derivados, a EP assume um interesse generalizado envolvendo qualquer área epistêmica cientifica (ALVES; SAMPAIO; VASCONCELOS \& BARROSO, 2016). Marty (2016, p. 8) detalha que "a Engenharia pedagógica é a correspondente que o formador desenvolve para otimizar sua relação com os aprendentes ou estudantes que visa formar".

Por fim, o design de investigação característico de uma ED possibilita uma prática de intervenção controlada, assumindo a relevância do entendimento pormenorizado dos fenômenos ensino-aprendizagem. Ademais, a despeito de que a primeira geração das engenharias desenvolvidas na França, desenvolveram uma maior atenção concernente à modelização das ações dos estudantes; no caso das engenharias da segunda geração, se observou um esforço dos especialistas com o interesse de modelizar e compreender, prever e antever a função do professor em todo o processo e sistema educativo.

\section{Considerações Finais}

Delineamos um cenário das investigação e evolução dos modelos investigativos, que culminaram com um processo de subdivisão de duas perspectivas distinguidas por ED1 e ED2. Ademais, apontamos ainda um papel fundamental para sua repercussão na formação de professores. Chevallard (1982, p. 5) recorda que, de acordo com a metáfora da engenharia didática, no que concerne ao papel do "engenheiro didático", o mesmo deve não apenas se amparar nos pressupostos da Ciência, mas, também, "levar em consideração em seu produto, de acordo com os cânones da Ciência". Ademais, "a engenharia possui como fím fornecer respostas das demandas visando modificar o real (a natureza) e articulando a teoria com o real" (CHEVALLARD, 1982, p. 5) e, assim, permite produzir um impacto na formação do professor de Matemática.

Acentuamos, ainda, um elemento imprescindível assumido como interesse em uma investigação apoiada nos pressupostos da ED e que, de modo prosaico é comentado por 
Chevallard (1982, p. 15) em termos da intenção de criar (controlar) fenômenos, visando o seu estudo sistemático. Mas, em nosso caso, como acentuamos aqui a tendência da ED2, assumimos posição concorde com Chevallard (1982, p. 16), quando distingue e diferencia elementos intrínsecos da ED e que devem ser distinguidos de uma pesquisa-ação ou abordagens amparadas pelo design qualitativo, por exemplo. Sua crítica reside em recordar que esta última modalidade de intervenção é apoiada por uma noção de "experimentalismo dogmático" e que não confere e não garante um caráter suficiente de cientificidade, significação e proximidade ao conhecimento matemático e sua trajetória funcional no sistema escolar. Historicamente, registramos nas seções anteriores um movimento francês de rejeição e contestação de um fenômeno parecido em solo europeu.

Por fim, desde que objetivamos a formação primária do professor (pesquisador), distinguimos as possíveis categorias epistemológicas da experiência, irremediavelmente gestadas da ação intencional do professor; dos procedimentos metodológicos de observação, visando a reprodução/replicação de engenharias de formação, tendo em vista o desenvolvimento optimal de suas ações no contexto que confere a sua identidade profissional, qual seja, a sala de aula. Por conseguinte, propugnamos com veemência uma crítica e questionamento de concepções, de um discurso ou retórica, cuja aparência acadêmica pode produzir no leitor mais interessado a sensação de um pseudo rigor científico, entretanto, se resume em um discurso vazio e distante da sala de aula, posto que suas reais e verdadeiras raízes estão bem distantes dos fenômenos que se originam no interior de uma aula de Matemática. Mais uma vez, o exemplo francês nos proporciona indeléveis ensinamentos.

\section{Referências}

ALVES, Francisco, R. V; SAMPAIO, Caroline, G; VASCONCELOS, A. K. P \& BARROSO, Maria, C. Didática das Ciências e Matemática: alguns pressupostos. Interfaces da Educação. v. 8, nº 22, 274 $-302,2016$.

ALVES, Francisco, R. V. Didática da Matemática: seus pressupostos de ordem epistemológica, metodológica e cognitiva. Interfaces da Educação. v. 8, n 22, 274 - 302, 2016.

ALMOUlOUD, Ag Saddo. Fundamentos da Didática da Matemática. São Paulo: Editora UFPR, 2007.

ARTIGUE, Michelle. (2002). Ingénierie didactique: quel rôle dans la recherche didactique aujourd'hui? Les dossiers des sciences de l'éducation. v. 1, n ${ }^{\circ} 8,2002$. Didactique des disciplines scientifiques et technologiques: concepts et méthodes. 59-72. Disponível em: http://www.persee.fr/docAsPDF/dsedu 1296-2104 2002 num 8 1 1010.pdf

ARTIGUE, Michelle. (2009). Didactical design in mathematics education. In C. Winslow (Ed.), Nordic Research in Mathematics Education. Proceedings from NORMA08 (p.7 - 16). Rotterdam: 
Sense Publishers, 2009. Disponível em: <https://isis.ku.dk/kurser/blob.aspx?feltid=212293 >. Acesso em: maio de 2017.

ARTIGUE, Michelle. (1989). Ingénierie Didactiques. ARTIGUE, Michelle. Institute des Recherche des Mathématiques Rennes, Disponível em: http://www.numdam.org/article/PSMIR_1989__S6_124_0.pdf

ARTIGUE, Michelle. (1984). Modélisation et reproductibilité en Didáctique des Mathématiques. Les Cahier Rouge, $\mathrm{n}^{\circ}$ 8, $1-22$.

BACHERLARD, Gaston. (1996). A formação do espírito científico. São Paulo: CONTRA-PONTO.

BROUSSEAU, G. Perspective pour la didactique des mathématiques: vingt ans de didactique des mathématiques en France. Paris: La Pensée Sauvage, 5 - 66, 1994.

BROUSSEAU, Guy. L’observation des activités didactiques. Revue Français de Pédagogie. $n^{\circ} 45$, 130-140, 1978.

BROUSSEAU, Guy. Théorisation des phénomènes d'enseignement de mathématiques. (Thèse d’État et Sciences). Bordeaux : Université de Bordeaux I, 1986.

BROUSSEAU, Guy. Didactiques des sciences et formation des professeurs. In : C. Comiti, T. Ngo Anh, A. Bessot, M.-P. Chichignoud \& J.-C. Guillaud (Eds.) Didactique des disciplines scientifiques et formation des enseignants, 34-54. Hà Nội: Maison d'Edition de l'Education, 1995.

BROUSSEAU, Guy. Les obstacles épistémologiques, problèmes et ingénierie didactique. In: BROUSSEAU, Guy. Théorie des situations didactiques, 115-160. Grenoble La Pensée Sauvage, 1998.

BROUSSEAU, Guy. Que peut-on enseigner en mathématiques à l'école primaire et pourquoi? Repère IREM, 38, 7-10, 2000.

BROUSSEAU, Guy. \& CRISTOL, Gilles. Les études doctorales de didactique des mathématiques à l'université. Gazette des mathématiciens, 85, 55-60, 2000.

BROUSSEAU, Guy. Fondement et méthode de la didactique de Mathématiques. In : BRUN, J. Didactique des Mathématiques. Paris : Délachaux et Niestle, 45-110, 1996.

CHEVAllarD. Y. Sur L’ingienierie Didactiques. IREM: d’Aix Marseille. Paris, 1 - 51. 1982. Disponível em: CHEVALLARD. Y. La Transposition didactique. Paris: La Pensée Sauvage Édition, 1991.

CHEVALLARD, Y. La notion d'ingénierie didactique, un concept à refonder. Questionnement et élémentos de réponses à partir de la TAD. in Margolinas et all.(org.) : En amont et en aval des ingénieries didactiques, $\mathbf{X V}^{\mathrm{a}}$ École d'Été de Didactique des Mathématiques - Clermont-Ferrand (Puy-de-Dôme). Recherches em Didactique des Mathématiques. Grenoble: La Pensée Sauvage, v. 1, p. 81-108, 2009.

CHOQUET, G. What is Modern Mathematics really?. Educacional Studies Limmited. 1963.

DOUADY, Régine. Jeux de Cadres et dialetique d'outil-objet dans l'enseignement de Mathématiques - une réalisation dans tout cursus primaire (thése d'État). Paris: Université Paris VII, 1984. 262f. 
DOUADY, R. La ingeniería didáctica y la evolución de su relación con el conocimiento. Artigue, M.; Douady, R.; Moreno, L. \& Gómez, P. (eds). Ingeniería didáctica en educación. 62 - 96, 1995.

GODINO, Juan. D, et all. Didactic engineering as design-based research in mathematics education. CERME, 2013.

MARGOLINAS, Claire. \& DRIJVERS, Paul. Didactical engineering in France; an insider's and an outsider's view on its foundations, its practice and its impact. ZDM Mathematics Education. v. 47, $n^{\circ} 6,893-903$. October, 2015.

MARTY, Pierre. A. Cours Ingénierie didactique. (Master Ingénierie de formation). France: Université de Lille. Disponível em: https://halshs.archives-ouvertes.fr/cel-01260590/document

GONDINO, Juan. D. et all. Didactic engineering as design-based research in mathematics education.
CERME,
2013,
p.
10.
Disponível
em:

<http://www.ugr.es/ jgodino/eos/Godino CERME 2013.pdf>. Acesso em: maio de 2017.

JOSHUA, Samuel. \& DUPIN, Jean-Jacques. Introduction à la Didactiques des Sciences et des Mathématiques. Paris: Presses Universitaires de France, 1993.

PASTRÉ, Pierre. Mayen, P. \& VERGNAUD, G. La didactique professionnelle. Revue française de pédagogie. 145 - 198, 2006. Disponível em: http://rfp.revues.org/

PASTRÉ, Pierre. La didactique professionnelle: Un point de vue sur la formation et la professionnalisation. Revue française de pédagogie, v. 5, 138 - 141. 2012. Disponível em: http://rfp.revues.org/3730

PERRIN-GLORIAN, M. J. (2011). L'ingénierie didactique a' l'interface de la recherche avec l'enseignement. De'veloppement de ressources et formation des enseignants. In: C. Margolinas, et al. (Eds.). En amont et en aval des inge'nieries didactiques, 57-78. Grenoble: La pense'e sauvage.

TEMPIER, Fréderick. New perspectives for didactical engineering: an example for the development of a resource for teaching decimal number system. Journal of Mathematical Teacher Education. v. $19, \mathrm{n}^{\mathrm{o}} 1,261-276.2016$.

Recebido em 07/07/2017 - Aceito em 06/11/2017 